\title{
ENDOTELINA-1: VASOCONSTRICTOR INTRÍNSECO DEL ENDOTELIO VASCULAR
}

\author{
NEIL FLORES VALDEZ \\ Médico internista. Docente de la Facultad de Ciencias de la Salud, Universidad Privada de Tacna. \\ Médico asistente del Servicio de Medicina del Hospital Daniel Alcides Carrión, Es Salud Tacna, Perú. \\ Miembro del comité editor de la Revista Médica de Tacna. \\ Correspondencia:neilflores@hotmail.com
}

Recibido: Junio 1 de 2013 Aceptado: Septiembre 5 de 2013

\begin{abstract}
Resumen
La endotelina es un péptido vasoconstrictor aislado inicialmente del cerdo de donde procede su denominación. Es considerado como el más potente vasoconstrictor conocido por el hombre, es incluso 10 veces más potente que la angiotensina II. Existen tres isoformas y están distribuidas en diversas células y tejidos interviniendo en la modulación del tono vascular, proliferación celular, producción hormonal, balance del sodio y como neurotransmisor. Para la regulación del tono vascular debe de haber un equilibrio de fuerzas vasoconstrictoras y vasodilatadoras generados por el endotelio o que ejercen influencia sobre el mismo, existen varios candidatos en la categoría de los vasoconstrictores, pero el más importante es la endotelina-1 por su potencia y su localización, ya que su acción es ejercida sobre el músculo liso vascular.
\end{abstract}

Palabras clave: Endotelina, vasocontrictor, músculo liso vascular.

\section{ENDOTHELIN-1: INTRINSIC VASOCONSTRICTOR VASCULAR ENDOTHELIAL}

\begin{abstract}
Endothelin is a vasoconstrictor peptide originally isolated pig whence its name. It is considered the most potent vasoconstrictor known to man, is even 10 times more potent than angiotensin II. There are three isoforms and are distributed invarious cells and tissues interveningin the modulation of vascular tone, cell proliferation, hormone production, sodium balanceandas a neurotransmitter. For the regulation of vascular tone must have a balance of vasoconstrictor and vasodilator forces generated by the endothelium or that influence it, there are several candidates in the category of vasoconstrictors, but the most important is theendothelin-1for its power and its location to beexertedits action on vascular smooth muscle.
\end{abstract}

Keywords: Endothelin, vasoconstriction, vascular smooth muscle. 


\title{
A ENDOTELINA-1: ENDOTELIAL VASCULAR VASOCONSTRITOR INTRÍNSECO
}

\begin{abstract}
Resumo
A endotelina é um peptídeo vasoconstritor, originalmente isolada de porco deu origem ao seu nome. Ele é considerado como o vasoconstritor mais potente conhecido do homem, é até 10 vezes mais potente que a angiotensina II. Existem três isoformas e são distribuídas em várias células e tecidos que intervêm na modulação do tónus vascular, proliferação celular, a produção da hormona, o balanço de sódio como um neurotransmissor. Para a regulação do tônus vascular vários candidatos devem ter um saldo de vasoconstrição e vasodilatação forças geradas pelo endotélio ou que a influência dele, existe na categoria de vasoconstritores, mas o mais importante é a endotelina- 1 em seu poder e localização, como sua ação é exercida sobre o músculo liso vascular.
\end{abstract}

Palavras-chave: endotelina, vasoconstrição, o músculo liso vascular.

Para que se produzca vasoconstricción es necesario que exista un incremento de calcio intracelular en las células del músculo liso vascular, proveniente del medio extracelular o por liberación del mismo de organelas intracitoplasmáticas fundamentalmente del retículo sarcoplásmico, para cumplir con este cometido, el organismo utiliza varios mediadores, podemos señalar que el mecanismo intrínseco dependiente del endotelio es el que mejor cumple con esta función siendo el "sistema endotelina" el más importante.

Bajo esta denominación de "sistema endotelina" se incluye a los genes de endotelina, péptidos como Preproendotelina, dos peptidasas activas, y tres péptidos de 21 aminoácidos denominados endotelinas unidos a receptores acoplados a Proteínas G.

Para la regulación del tono vascular debe de haber un equilibrio de fuerzas vasoconstrictoras $\mathrm{y}$ vasodilatadoras generados por el endotelio o que ejercen influencia sobre el mismo, existen varios candidatos en la categoría de los vasoconstrictores, pero el más importante es la endotelina por su potencia y su localización al ser ejercida su acción sobre el músculo liso vascular. Realizaré una descripción dinámica, que permita conocer y comprender como está estructurada y como cumple su función este sistema. Básicamente describiré lo acontecido por endotelina 1(ET-1) por ser la más potente y estar mayormente implicado en la fisiología y fisiopatología humana más que las otras dos endotelinas.

\section{Endotelina}

El 1984, O'brien y McMurthy observaron que después de 6 horas una muestra de suero obtenida de un medio de cultivo de células endoteliales de aorta de bovino lograba producir una vasoconstricción de las arterias pulmonares de bovino. Además, estudios realizados en 1985 por Hickey et al. en arterias coronarias donde encontraron que las células endoteliales producían incremento de la tensión dependiente de volumen y que esta propiedad era abolida por compuestos que desnaturalizaban proteínas, por esos años se propuso que ésta sustancia debería ser un péptido vasoactivo, y le denominaron factor contráctil derivado del endotelio $(1,2,3)$. Posteriormente en el laboratorio del profesor Masaki de la Universidad de Tsukuba en Japón, un grupo de investigadores comandados por Masashi Yanagisawa y Hiroki Kurihara iniciaron la purificación de este péptido contráctil, en el año 1998 logra ser aislada del sobrenadante del medio de cultivo de células del endotelio vascular de aorta porcina y le acunaron la denominación de endotelina, porque inicialmente fue aislada del cerdo. Este nuevo péptido identificado como un péptido vasoconstrictor potente tiene un peso molecular de $2492 \mathrm{Da}$. y es considerado como el más potente vasoconstrictor conocido por el hombre $(4,5)$. Desde ese año y hasta la fecha se han realizado más de 18.000 publicaciones por diversos investigadores del mundo con la finalidad de lograr conocer sus propiedades biológicas y encontrar sus aplicaciones clínicas a favor de la comunidad médica mundial (6). 


\section{Endotelina 1(ET-1)}

Es un péptido de 21 aminoácidos con propiedades vasoconstrictoras, considerado como el vasoconstrictor más potente actualmente conocido incluso 10 veces más potente que angiotensina II $(7,8,9)$. Posteriores estudios determinaron que las endotelinas son una familia y está conformada por 3 péptidos de 21 aminoácidos ET-1, 2 y 3, con una estructura peptídica muy similar. Las endotelinas están distribuidas en una variedad de células y tejidos, con diferentes niveles de expresión, donde actúan como moduladores del tono vasomotor, proliferación celular, producción hormonal, balance del sodio, neurotransmisión y desarrollo de la cresta neural $(10,11,12)$.

\section{Estructura y biosíntesis de endotelinas}

\section{Estructura de endotelina -1(ET-1)}

La endotelina-1, es un polipéptido que está conformado por 21 aminoácidos. Hay 3 isoformas estrechamente relacionadas: endotelina -1, endotelina-2 y endotelina-3 (ET-1, ET-2, ET-3 respectivamente), que difieren en pocos aminoácidos constitutivos. Existe una cuarta isoforma de endotelina denominada ET-4 o péptido intestinal constrictor (VIC) encontrado en ratas y ratones, que es análogo a ET-2 de los humanos $(13,14)$. La endotelina-1(ET-1) está constituida por 21 aminoácidos con cuatro residuos de cisteína, estableciendo dos puentes intramoleculares de disulfuro y formando una estructura semicónica inusual. Los puentes de disulfuro y el dominio carboxiterminal son cruciales, tanto para la unión de la endotelina con su receptor específico como para conservar su actividad biológica (10).

Sí queremos comparar a la ET-1 con las otras endotelinas, es decir, ET-2 y ET-3 y reconocer que estructuras conservan entre sí, entonces se pueden mencionar que se encuentran los 6 aminoácidos que se ubican en el terminal carboxilo y los residuos de cisteína que forman puentes disulfuro uniendo residuos $1-15$ y 3-11. Estos residuos podrían tener implicancias biológicas, particularmente en relación con su estructura tridimensional y función biológica (14). En cuanto a las diferencias entre estas endotelinas estructuralmente se establece en el extremo amino-terminal, tanto así que la ET-2 y ET-3 difiere de ET-1 por 2 y 6 aminoácidos respectivamente (15). En la figura 1 podemos observar la estructura de la ET-1, se evidencia la característica cónica de las mismas y la disposición de los puentes disulfuro. Se ha reportado adicionalmente la presencia de una endotelina- 1 con una secuencia mayor de aminoácidos (endotelina 1-31), cabe señalar que esta endotelina conserva también la estructura de las otras pero su diferencia radica en su potencia, se menciona que es menos potente que su equivalente de $21 \mathrm{ami-}$ noácidos (16).

Existe similitud entre la familia de las endotelinas y un grupo de sustancias encontradas en el veneno de serpientes de la familia Atractaspis Engadensis llamadas sarafotoxinas (el veneno del áspid, con el cual se suicidó Cleopatra), ocasionado un espasmo coronario, infarto y fibrilación ventricular. Es decir "Cleopatra murió de una sobredosis de endotelina" (17). La sarafotoxina $6 \mathrm{~B}$, comparte una estructura química similar a ET-1, diferenciada en 7 aminoácidos y una capacidad vasoconstrictora potente y sostenida. La relación de ambos péptidos en la escala evolutiva animal se ve apoyada por el hecho de que posiblemente pertenezcan a la misma familia genética, aunque el mRNA de la sarafotoxina GB sólo ha sido identificada en las glándulas exocrinas productoras del veneno de la serpiente, sin relación alguna con el endotelio vascular $(4,18)$.

Las características de la actividad biológica de las endotelinas se debe a la secuencia heterogénica de la región amino-terminal, probablemente la región de aminoácidos de la secuencia desde treonina $2 \mathrm{a}$ lisina 7 es importante para unirse con su receptor específico y mantener su característica vasoconstrictora $\mathrm{y}$ vasopresora.

La apertura de un puente disulfuro también produce disminución de su actividad vasoconstrictora. La disminución de la actividad vasoconstrictora también se ha visto cuando se cambian los aminoácidos en la región carboxilo terminal del péptido, pero su efecto es menos importante que el señalado en la región amino-terminal $(19,20)$.

\section{Biosíntesis y regulación de la producción de endotelina -1 (ET-1)}

La endotelina-1, (ET-1) es sintetizada en diferentes tipos celulares como por ejemplo: las células del endotelio, las del músculo liso vascular, del epitelio bronquial, los leucocitos, los macrófagos, los cardiomiocitos y las células mesangiales por mencionar algunas de ellas. Cada endotelina es sintetizada en diferentes células, tejidos, y órganos, cabe señalar que esta síntesis va- 
Figura 1. Estructura de laendotelina-1. La de tipo ET-1(1-21), presenta dos puentes disulfuro en posición 1,311y 15 (en color azul) y otra de tipo ET-1 (1-31), presenta dos puentes disulfuro en posición 1,3, 11 y 15 (en color azul), adicionalmente esta última presenta una cadena polipeptídica de 10 aminoácidos adicionales (color violeta), por el extremo C Terminal. Adaptado de Masaki T. TRENDS in Pharmacological Sciences (2).

\section{Big Endotelina -1}

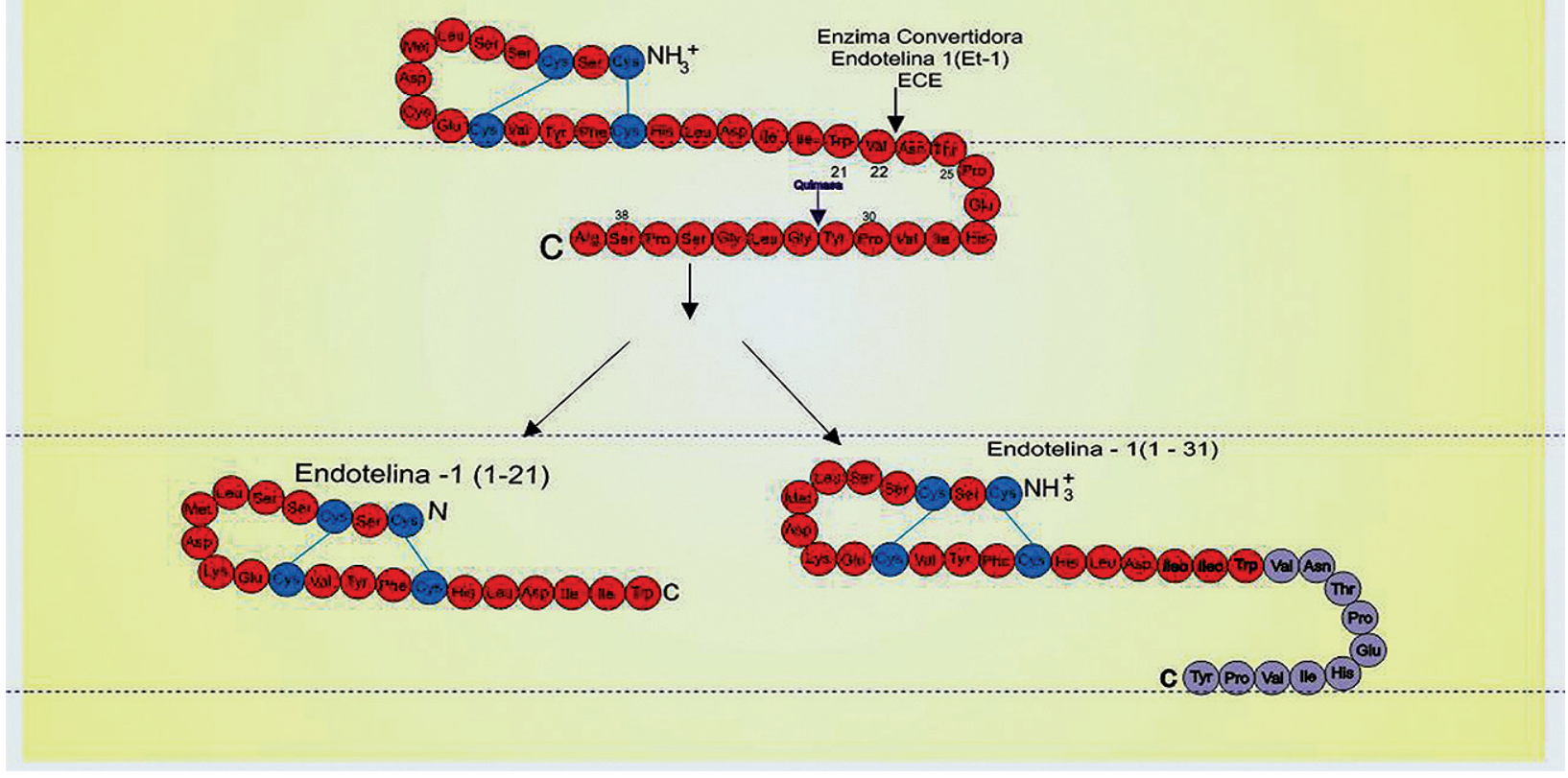

ría dependiendo de la estructura, órgano y tejido en estudio. En la tabla 1 se presentan las diversas células implicadas en la síntesis de cada endotelina, de esta tabla se destaca que ET-1 se produce en mayor concentración en células endoteliales, la ET-2 mayormente en células epiteliales renales y células del estroma y
ET-3 en el cerebro fundamentalmente en las neuronas y células de la glía $(3,13,21,22,23)$. Cada uno de los péptidos: endotelina-1 (ET-1), endotelina-2(ET-2) $y$ endotelina-3(ET-3), es codificado por un gen independiente en un cromosoma determinado 6,1 y 20 respectivamente (7).

Tabla 1. Lugares de Producción de ET-1, ET-2, ET-3

\begin{tabular}{|c|c|c|c|}
\hline ET-1 & ET-2 & ET-3 & Referencias \\
\hline $\begin{array}{l}\text { Células endoteliales }\left({ }^{*}\right) \\
\text { Corazón } \\
\text { Células del músculo liso vascular } \\
\text { Células epiteliales renales } \\
\text { Hepatocitos } \\
\text { Células del estroma neural } \\
\text { Células del astrocito } \\
\text { Pituitaria posterior } \\
\text { Células mesangiales renales } \\
\text { Células de Sertoli } \\
\text { Células endometriales } \\
\text { Células epiteliales de la mama } \\
\text { Leucocitos (monocitos, neutrófilos) } \\
\text { Células túbulo renal } \\
\text { Ojos } \\
\text { Cerebelo } \\
\text { Queratinocitos } \\
\text { Neuronas postganglionares }\end{array}$ & $\begin{array}{l}\text { Células epiteliales renales }(*) \\
\text { Células del estroma }(*) \text { gastrointestinal, colon, } \\
\text { Intestino y corazón } \\
\text { Placenta } \\
\text { Útero } \\
\text { Ovario }\end{array}$ & $\begin{array}{l}\text { Neurona }(*) \\
\text { Glía }(*) \\
\text { Células adrenales } \\
\text { Células epiteliales de pulmón } \\
\text { Intestino }(*) \\
\text { Células epiteliales renales } \\
\text { Plasma } \\
\text { Corazón }\end{array}$ & $\begin{array}{l}(3,4,6,10) \\
(11,13,24) \\
(7,8,21,25) \\
(15,26,27) \\
(16,22,28,29)(30) \\
(23)\end{array}$ \\
\hline
\end{tabular}




\section{Biosíntesis y regulación de la producción de ET-1}

\section{Biosíntesis de ET-1}

Para el caso de la biosíntesis de ET-1, que es el más caracterizado por cuanto interviene en la regulación del tono vascular y que se produce en mayor concentración en el endotelio por células endoteliales. Se puede señalar que se desarrolla en el citosol de estas células y que los más potentes estimulantes en la síntesis de esta endotelina son la hipoxia, la isquemia y las alteraciones hemodinámicas de la fuerza de rozamiento vascular (shear stress). De forma opuesta, los inhibidores de su síntesis fundamentalmente es acontecida por óxido nítrico, vasodilatadores dependientes de nitratos, prostaciclina y péptido natriurético auricular (25). En la tabla 1 se exponen las células, tejidos y órganos que producen las diversas endotelinas.

El mRNA de ET-1 humana codifica la Preproendotelina de 212 aminoácidos a través de la activación proteolítica de una endopeptidasa la transforma en Big- endotelina-1 de 39 aminoácidos (Big-ET-1). Este fragmento posteriormente sufre la acción de la enzima convertidora de endotelinas (ECE-1) de las que existe en cuatro isoformas $(\mathrm{a}, \mathrm{b}, \mathrm{c}, \mathrm{d})$. Fundamentalmente hay dos isoformas que intervienen en el clivaje de Big- ET-1; la isoforma ECE-1aes expresado en el aparato Golgi de las células que producen endotelina, las células endoteliales poseen esta isoforma y logra el clivaje de Big-ET-1 intracelular, también se debe señalar que estas mismas células endoteliales poseen la isoforma ECE1b, la que está localizada en la membrana celular y su función es clivar Big-ET-1 extracelular $(2,30)$. La enzima convertidora de endotelina (ECE), es una metaloendoproteinasa, que pertenece a la superfamilia de la neprilisina (zinc metaloproteinasa unida a membrana), cuya máxima acción es a pH de 7.40 (11). Esta enzima rompe la unión en la posición triptófano 21-valina 22(Trp21-Val22), transformándola en endotelina -1 de 21 aminoácidos (ET-1), siendo este péptido activo. $(14,15,24)$. La ET-1 formada es un polipéptido 140 veces más potente que Big-ET-1 (26) y es la que ejerce efectos biológicos.

Adicionalmente a este mecanismo descrito para la formación de ET-1, se ha descrito otro mecanismo paralelo para la formación de endotelina-1, esta otra vía contempla la presencia y acción de los mastocitos. Se ha encontrado que estas células contienen gránulos citoplasmáticos los cuales una vez que son estimulados liberan varios autacoides como citoquinas, proteoglucanos y unas enzimas denominadas proteínas serinas como la quimasa, quimotripsina, catepsina $G$ y caboxipeptidasa A. La quimasa se ha encontrado localizada en el espacio intersticial seguido a la de granulación de las células cebadas sometidas a estímulos, esta enzima puede actuar sobre Big ET-1 logrando clivarla a nivel de sus residuos Tyr 31-Gly32, resultando una endotelina-1(ET-1) de 31 residuos (1-31), esta enzima se ha descrito que tiene efectos vasoconstrictores pero de menor potencia que su homóloga de 21 aminoácidos, aún falta definir su exacta fisiología y fisiopatología $(16,28)$. En la figura 1 se expone la estructura de las endotelinas- 1 , así como las zonas de clivaje y las enzimas que ejercen su función.

Cuando la célula endotelial es expuesta a un estímulo, la liberación de endotelina-1 se presenta a los pocos minutos y su tiempo de vida media plasmático es corto, para la mayoría de los autores coinciden que es de 4 a 7 minutos, aunque otros proponen que es menos de 2 minutos (28), mientras que el mRNA de ET-1 alcanza un máximo de 15 a 20 minutos de vida media (14). El corto tiempo de vida media de ET-1 se debe a la capacidad que tiene el organismo en su degradación y posterior eliminación, podemos señalar que los órganos mayormente implicados en la extracción de ET-1 son el pulmón y el riñón, tanto es así que en la primera pasada por el pulmón se extrae del plasma más del $50 \%$ incluso algunos autores mencionan que se extrae hasta $70 \%$ de ET-1. Los mecanismos que logran un retiro efectivo a nivel pulmonar tienen que ver con el receptor de ET-1 de tipo B (ETB), el mecanismo íntimo de estos hechos aún no se han aclarado del todo, pero los estudios han demostrado que depende de dos vías; la primera explica que una vez que toma contacto la ET-1 con su receptor ETB se produce una internalización del complejo formado ET-1/ETB en el citoplasma de la células endoteliales del pulmón y que posteriormente sufre la degradación por acción de los lisosomas y la segunda posibilidad es porque los receptores ETB están más accesibles a las endotelinas que los de tipo ETA, por cuanto el pool de ETB está en las células endoteliales $(3,24)$. A nivel renal la ET-1 puede ser degradada por la endopeptidasa neutral (NEP), la cual están localizada cerca de las vesículas que contienen ET-1 en el tubo contorneado proximal, es por esta razón que la concentración de ET-1 varía inversamente con la función renal $(3,16)$. 


\section{Liberación de ET-1 en los vasos sanguíneos.}

Existe discrepancias en la literatura sobre su almacenamiento en las células endoteliales, pero lo que sí se ha logrado precisar es que hay dos formas de liberación de ET-1, teniendo en cuenta el estímulo se menciona que son dos vías; la primera, es la vía denominada "vía constitutiva", por esta vía se libera endotelina-1 constantemente, es sintetizada por ECE-1/ ECE-2 produce intensa constricción en el músculo liso vascular adyacente y contribuye con el mantenimiento endógeno del tono vascular, y la segunda es la llamada "vía regulada", por esta vía la ET-1 esta almacenada en los cuerpos de Weibel- Palade y se libera posterior a estímulos fisiológicos o fisiopatológicos y produce una marcada vasoconstricción $(6,14,18,32,33)$. Las células endoteliales liberan ET-1 como mínimo el 75\% hacia la capa media de los vasos sanguíneos sugiriendo un rol paracrino/autocrino (28). Estudios en adultos sanos muestran que los niveles basales de ET-1 son 0.7 a 5 $\mathrm{pg} / \mathrm{ml}$ y que la excreción urinaria en 24 horas de ET-1 es el mejor predictor del nivel de ET-1 plasmático, en adultos normales la excreción urinaria de ET-1 está entre $1,7 \mathrm{pg} / \mathrm{ml}$ y $6,8 \mathrm{ng} / \mathrm{ml}(8,34,35)$. En la figura 2 se hace una representación de la liberación de endotelina -1 por las células endoteliales, así también cómo se efectúa su eliminación.

Figura 2. Liberación de endotelina-1 por las células endoteliales. Por la vía constitutiva la ET-1 se libera constantemente contribuyendo con el mantenimiento endógeno del tono vascular, por la vía regulada la ET-1 es almacenada en los cuerpos de Weibel-Padale y es liberada por estímulos fisiológicos y fisiopatológicos. Modificado de Moncada S et al. The vascular endothelium I. Springer-Verlag Berlin Heidelberg (6).

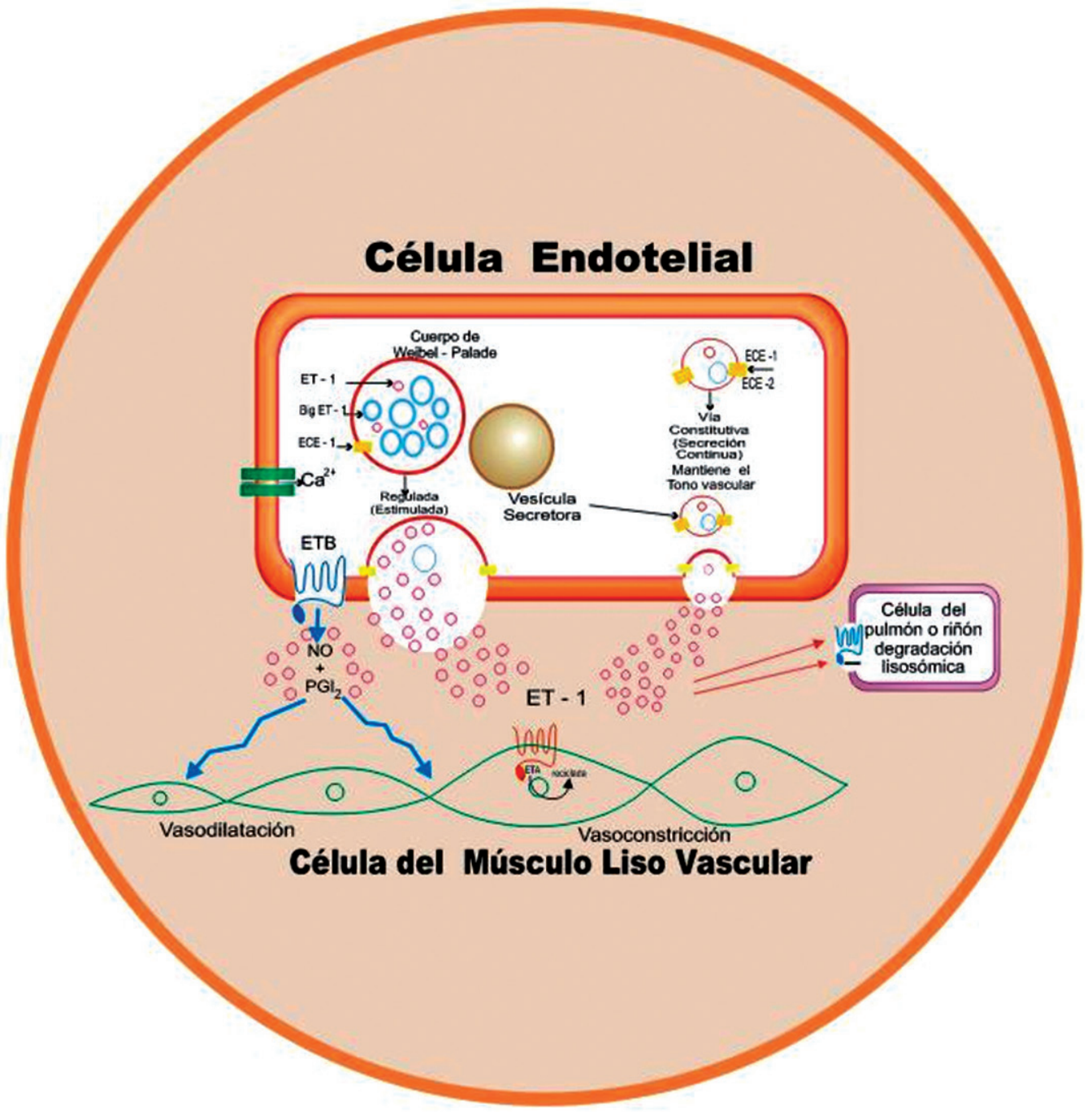




\section{Receptores de endotelinas}

Se han caracterizado dos tipos de receptores de alta afinidad que pertenecen a la superfamilia de receptores acoplados a Proteína $\mathrm{G}$, a través de las cuales median sus efectos las endotelinas $(8,10)$. Los receptores de endotelinas han sido clasificados como receptores de endotelinas tipo A (ETA) y tipo B (ETB) por el Comité Farmacológico Internacional de Nomenclatura y Clasificación de Drogas (NC-IUPHAR), esta clasificación proviene de estudios enfocados en la expresión de receptores en varios tejidos de diferentes especies y el desarrollo de antagonistas, particularmente no peptídicos (18).

\section{Receptor de Tipo A (ETA)}

El receptor de tipo A (ETA) fue inicialmente clonado en pulmón de bovinos y ratas. En humanos el receptor ETA ha sido clonado y localizado en el cromosoma 4 (26). Este receptor tiene una longitud de 427 aminoácidos, y tiene una secuencia en $94 \%$ a $91 \%$ es idéntica a la obtenida en bovinos. Es predominantemente expresado en las células del músculo liso vascular y miocitos cardíacos, aunque también se han descrito en la vía aérea, células estrelladas hepáticas, hepatocitos, neuronas, osteoblastos, melanocitos, adipocitos y células del sistema reproductor. En la tabla 2 se expone los lugares donde se realiza la expresión de receptores ETA. Se ha establecido que existen dos subtipos de receptores de ETA, es así que tenemos dos subtipos; ETA1 y ETA2, estos al interaccionar con ET-1 genera vasoconstricción y proliferación celular $(3,36)$.

Tabla 2. Función de receptores a endotelina-1 (ET - 1) a nivel cardiovascular.

\begin{tabular}{|c|c|c|c|}
\hline Tipo Celular & Receptor ETA & Receptor ETB & Referencias \\
\hline $\begin{array}{l}\text { Orden de potencia } \\
\text { Predominancia en su expresión } \\
\text { a nivel de los tejidos } \\
\text { Tejido cardíaco } \\
\text { Tipos de vaso } \\
\text { Funciones en general } \\
\text { Funciones por tipo celular } \\
\text { Células endoteliales } \\
\text { Célula del músculo liso } \\
\text { Fibroblastos cardíacos } \\
\text { Cardiomiocitos }\end{array}$ & $\begin{array}{l}\text { ET - 1>ET - 2>ET - } 3 \\
\text { Músculo liso vascular(*), } \\
\text { cardiomiocitos, fibroblastos } \\
\text { Miocito > fibroblastos } \\
\text { Conductancia y resistencia } \\
\text { Vasoconstricción } \\
\text { Mitogénesis } \\
\text { Angiogénesis } \\
\text { Formación de la matriz extracelular } \\
\text { Proinflamatorio } \\
\text { Apoptosis } \\
\text { Fibrosis } \\
\text { Vasoconstricción y proliferación } \\
\text { Proliferación y fibrosis } \\
\text { Hipertrofia, inotropia(+) }\end{array}$ & $\begin{array}{l}\text { ET-1 }=\text { ET-2 }=\text { ET-3 } \\
\text { Endotelio, músculo liso vascular } \\
\text { Fibroblastos > miocitos } \\
\text { Todos los vasos } \\
\text { Vasodilatación } \\
\text { Natriúresis } \\
\text { Eliminación de ET-1 } \\
\text { Vasoconstricción } \\
\text { Previene la apoptosis } \\
\\
\text { Vasodilatación a través de la } \\
\text { Producción de NO y PI2. } \\
\text { Incremento de la expresión que } \\
\text { en ET - 1 } \\
\text { Vasoconstricción } \\
\text { Proliferación y fibrosis } \\
\text { Cronotropia(+), hipertrofia }\end{array}$ & $\begin{array}{l}(3,4,10,11,21,24,28) \\
(18,14,32) \\
(37)\end{array}$ \\
\hline $\begin{array}{l}\text { (*) Células con mayor expresión } \\
\text { de ET-1. } \\
\text { (+) Células donde cumplen mayor } \\
\text { función. }\end{array}$ & & & \\
\hline
\end{tabular}

\section{Receptor de Tipo B (ETB)}

Este receptor está codificado en el cromosoma 13 (21), y está conformado por una secuencia de 442 aminoácidos, esta secuencia es semejante en $89 \%$ y $88 \%$ a los receptores ETB de bovinos y ratas respec- tivamente (35). En humanos, es predominantemente expresado en las células endoteliales y está unida a la Proteína $\mathrm{G}$ inhibitoria (Gi). Los factores moduladores que logran incrementar o disminuir su expresión están representados en la tabla 3.Los receptores ETB tienen dos subtipos, el subtipo ETB1, que media vasodila- 
tación y ETB2 vasoconstricción (36). Sin embargo, la vasoconstricción en respuesta al receptor ETB es variable depende del tipo, tamaño y de la especie en estudio (3).

Los receptores de endotelinas ETA y ETB han sido clasificados sobre la base de su afinidad con las diversas endotelinas. Los receptores ETA, tiene 100 veces más afinidad para ET-1 si lo comparamos con ET-3. Los receptores ETB tienen tiene afinidad semejante para los tres endotelinas. En humanos, la secuencia de aminoácidos para ETA y ETB exhibe una similitud en 59\% (14). En la tabla 2 se expone las funciones de los receptores de endotelinas a nivel cardiovascular y la afinidad de las endotelinas por cada receptor. En situaciones patológicas la densidad de los receptores varía, por ejemplo, en ratas con insuficiencia cardíaca crónica la relación de ETA:ETB que en condiciones normales es de 85:15 varía a 50:50, en estas condiciones patológicas habría una mayor cantidad de receptores ETB (38).

Tabla 3. Factores moduladores de la síntesis de receptores de endotelina.

\begin{tabular}{|c|c|c|c|c|}
\hline \multicolumn{2}{|c|}{ Factores que estimulan } & \multicolumn{2}{|c|}{ Factores que inhiben } & \multirow{2}{*}{ Referencias } \\
\hline Receptor tipo ETA & Receptor tipo ETB & Receptor tipo ETA & Receptor tipo ETB & \\
\hline $\begin{array}{l}\text { - Hipoxia, ciclosporina } \\
\text { - Factor de crecimiento } \\
\text { epidérmico (UEGF) } \\
\text { - Factor de crecimiento de } \\
\text { fibroblasto } \\
\text { - Estrógeno } \\
\text { - AMPc } \\
\text { - Isquemia }\end{array}$ & $\begin{array}{l}\text { - Péptido natriurético tipo C } \\
\text { - Angiotensina II } \\
\text { - Factor de crecimiento de } \\
\text { fibroblastos }\end{array}$ & $\begin{array}{l}\text { Endotelina } \\
\text { Angiotensina II } \\
\text { Factor de crecimiento de } \\
\text { plaquetas } \\
\text { Factor de crecimiento } \\
\text { transformante } \beta \text {. }\end{array}$ & $\begin{array}{l}\text { AMPc } \\
\text { Catecolaminas }\end{array}$ & $\begin{array}{l}(3,14,28,30) \\
(32)\end{array}$ \\
\hline \multicolumn{5}{|c|}{ Agonistas selectivo del receptor de endotelina } \\
\hline ninguno & $B Q-3020$ & & & \\
\hline \multicolumn{5}{|c|}{ Antagonista selectivo del receptor de endotelina } \\
\hline $\mathrm{BQ}-123$ & $\mathrm{BQ}-788$ & & & \\
\hline
\end{tabular}

\section{Función de las endotelinas}

\section{Endotelina -1 (ET-1)}

La ET-1 ejerce su acción a nivel vascular en forma directa sobre sus receptores de tipo $\mathrm{A}$, (ETA) produciendo vasoconstricción fundamentalmente y cuando hace contacto con su receptor de tipo $\mathrm{B}$ produce vasodilatación. También se ha descrito una acción indirecta sobre otros vasoconstrictores conocidos haciendo que estos incrementen su liberación.

Se puede mencionar entonces que la ET-1 ejerce su función a nivel vascular de dos maneras: una de ellas que depende de sí misma o de acción directa y otra lo hace sensibilizando a estructuras intracitoplasmáticas para mejorar o disparar su función constrictora, a esta forma se le llama de acción indirecta, ahora haremos una descripción de cada una de ellas:
Acción directa de ET-1 sobre receptor ETA.

En individuos sanos, los niveles plasmáticos de ET-1 medidos por radio inmunoensayo, es de 1.5 a $3.7 \mathrm{pg} /$ $\mathrm{mL}$, estos niveles son aproximadamente de 10 a 100 veces más bajos que los necesarios in vitro para producir vasoconstricción, la razón de esta baja concentración está relacionada con la rápida remoción de ET-1 de la circulación (15), pero el efecto vasoconstrictor se va incrementando progresivamente y permanece por aproximadamente una hora, estos hechos probablemente derivan del ingreso de calcio extra citoplasmático $(7,8)$. El EC50 para que ET-1 produzca vasoconstricción esta entre 0.1 a $1 \mathrm{nM}$, esta concentración ha sido obtenida de preparados de células del músculo liso vascular (35). Su efecto vasoconstrictor e inotrópico positivo se logra a través del incremento del calcio en el citosol. Para este efecto, la ET-1 se une a su receptor específico ETA en el sarcolema, de la célula del músculo liso 
vascular activando a la fosfolipasa C, esta activación induce hidrólisis de los lípidos de inositol localizados en la membrana, formando dos segundos mensajeros, inositol 1,4,5-trifosfato (IP3) y diacilglicerol (DAG) $(4,13,15)$. El IP3 hace contacto con su receptor en la superficie del retículo sarcoplásmico, esta unión logra liberar calcio del mismo hacia el citosol produciéndose un incremento inicial y transitorio de calcio, se ha descrito también que el retículo sarcoplásmico puede libera calcio por la vía de la cafeína sensible (19). Por otro lado, la vía del diacilglicerol (DAG) activa la proteincinasa $\mathrm{C}$ (PKC), incrementa la sensibilidad del aparato contráctil al calcio, ésta va a fosforilar a las cadenas ligeras de miosina para iniciar la contrac- ción de la fibra muscular lisa, otras funciones que se asocia a PKC es la activación de la compuerta $\mathrm{Na}+/$ $\mathrm{H}+$, aumentando finalmente la entrada de calcio a la célula del músculo liso $(4,17,25,34)$. En la figura 3, se esquematiza las diversas vías de transducción de los receptores de endotelina y la activación de PKC, vía necesaria para producir constricción. La ET-1 causa un incremento bifásico de la concentración de calcio al interior de las células del músculo liso vascular, esto consiste en un incremento transitorio seguido por un incremento sostenido del calcio intracelular. El incremento transitorio está relacionado con el movimiento del calcio intracelular por activación de la fosfolipasa C (PLC) (2).

Figura 3. El presente esquema muestra las diversas vías de transducción de los receptores de endotelina. Todos los efectos son mediados inicialmente por la interacción con la Proteína $G$, dentro de todo este proceso la activación de las múltiples isoformas de proteincinasa $C$ $(P K C)$ son claves en el proceso de señalización de endotelina -1. Proteína quinasa activada por mitógeno (MAPK). Modificado de Vallance P. et al. Vascular endothelium in human physiology and pathophysiology. Taylor and Francis (7).

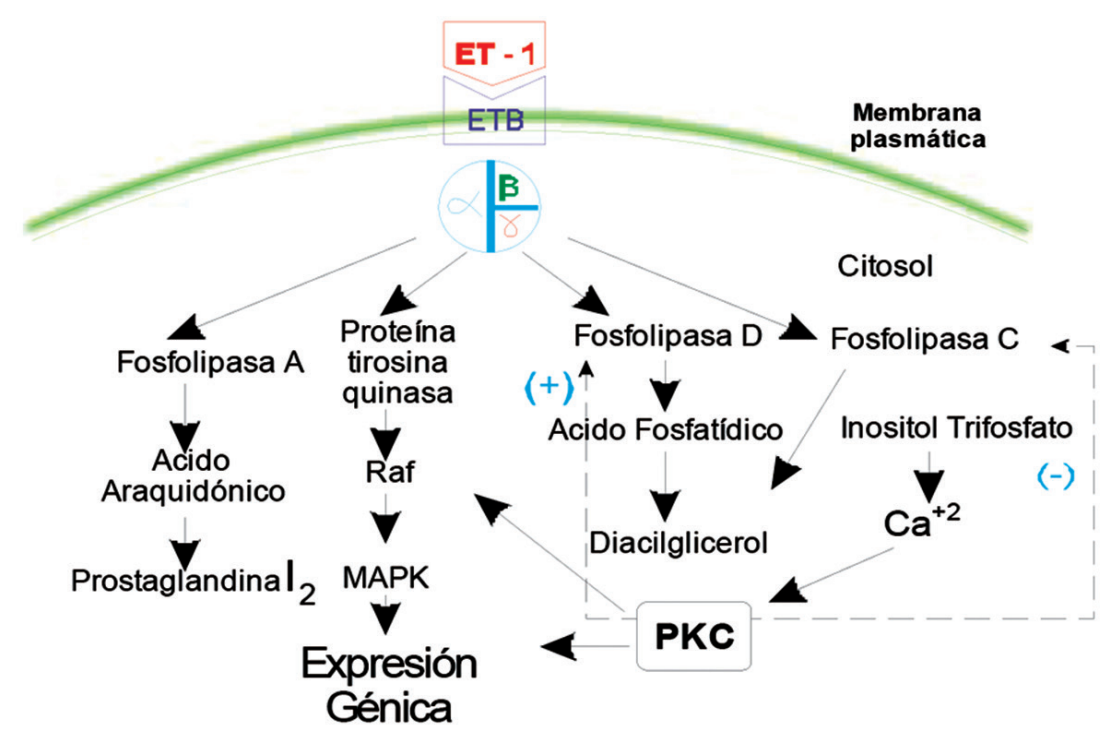

Célula del músculo liso vascular

El incremento sostenido es debido al influjo del calcio extracelular. El ingreso de calcio extracelular dependiente de ET-1 está sujeto a la apertura de los canales de calcio de tipo L, sin embargo, se ha sugerido que pueden estar implicadas otras vías como los canales catiónicos no selectivos para el calcio y los canales operados por almacenamiento de calcio (SOCC) $(2,15)$. La ET-1 activa a fosfolipasa D (PLD) en varios tejidos. La PLD cataliza la hidrólisis de fosfolípidos y produce ácido fosfatídico que luego pueden ser convertidos a DAG así, la activación de PLD puede guiar la producción sostenida de DAG. Adicionalmente, ET-1 puede activar fosfolipasa A2, favoreciendo la producción de prostaglandinas, las cuales pueden contribuir con la acción contráctil de ET-1 (13,14,15,25). A nivel citoplasmático la ET-1 puede cumplir con otras de las funciones como es la activación de la cascada proteína quinasa activada por mitógeno (MAPK), por esta vía contribuye con el control del crecimiento celular, adhesión y migración en la vasculatura y el corazón (13). En la figura 4, se hace una representación gráfica del accionar en la formación de endotelina - 1 y su interacción con receptores ETA y ETB sobre la célula del músculo liso vascular. 
Figura 4. ET-1 y su interacción con la pared vascular. La ET-1 hace contacto sobre las células endoteliales a través de su receptor de tipo $B$, esta interacción produce la liberación de óxido nítrico (NO) y prostaglandina I2 (PGI2), estos difunden hacia el músculo liso vascular adyacente y genera vasodilatación. Cuando la ET-1 hace contacto en las células del músculo liso vascular hace contacto con receptores de tipo $A$ y B, producto de esta interacción se produce vasoconstricción a través de la liberación de calcio intracelular. Modificado de Masaki T et al. Circulation (19).

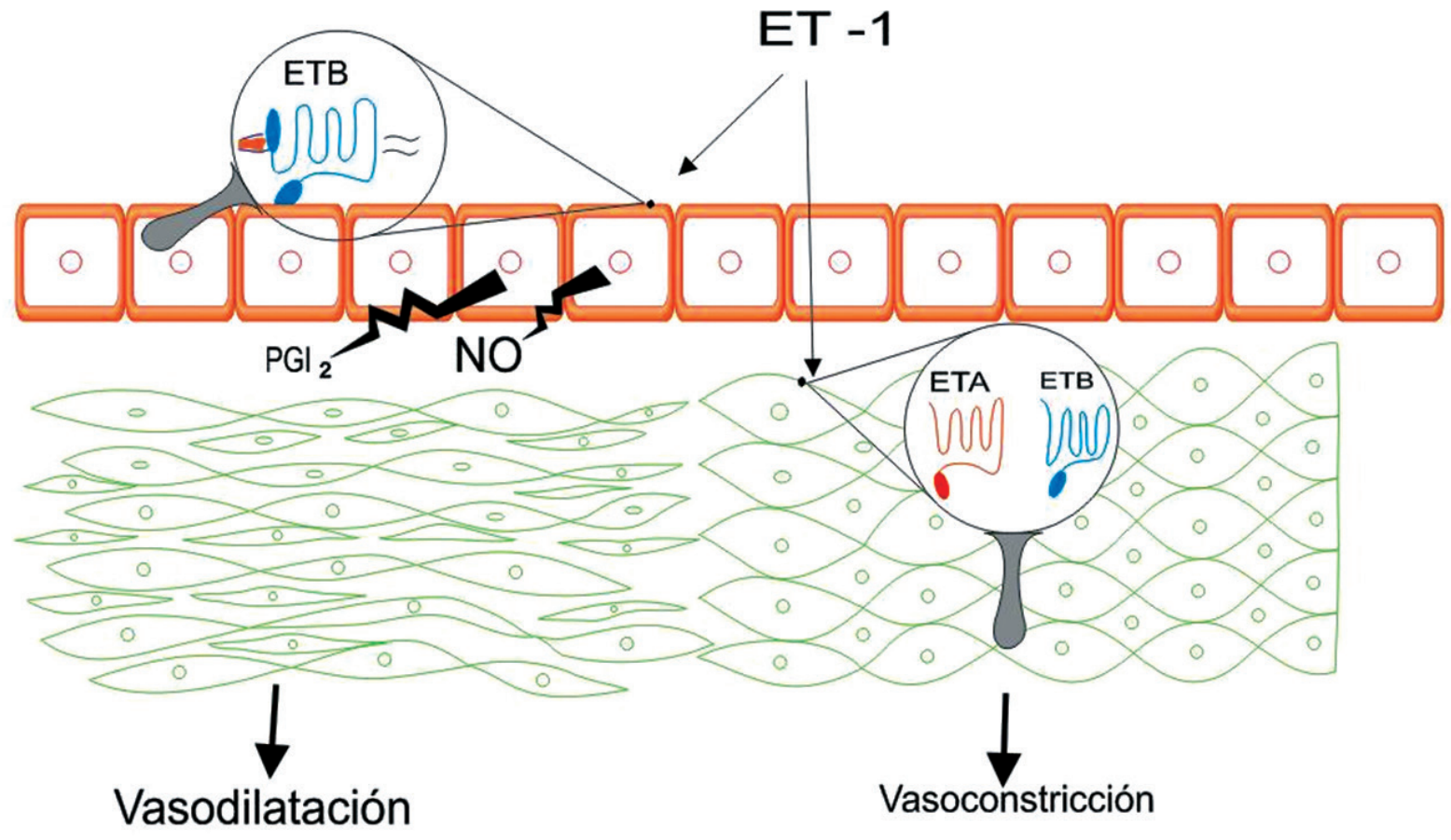

\section{Acción directa de ET-1 sobre receptor ETB}

Los receptores ETB son acoplados a Gq/G11 y su posterior activación recluta vías dependientes de PLC, PLA2, PLD, Intercambiador $\mathrm{Na}+/ \mathrm{H}+$, adelinato $y$ guanilato ciclasa.

La movilización de calcio intracelular y la entrada del mismo a la célula, así como las vías de señalización dependientes de fosfatidilinositol 3-cinasa (PI3K) y la subunidad $\beta / \gamma$ de la Proteína $G$, se producen posterior a la interacción de ET-1 y ETB $(13,22)$. Cuando ET-1 toma contacto con receptor ETB a nivel de las células endoteliales va a producir relajación del endotelio a expensas del incremento del GMPc, esto producirá liberación del óxido nítrico (NO) y EDHF. Este receptor va a permitir modular la respuesta vasoconstrictora de ET-1 $(9,35)$.

\section{Acción indirecta de la ET-1}

Esta acción la ejerce sobre otros vasoconstrictores conocidos como norepinefrina, serotonina y angiotensina II, haciendo que se liberen en mayor concentración y logrando incrementar el tono vascular, este hecho se denomina sensibilización de los vasos sanguíneos por parte de ET-1 a otros vasoconstrictores. Esta acción se produce a concentraciones de ET-1 menor que las observadas para producir vasoconstricción directamente dependiente de ET-1, estas concentraciones menores a $0.1 \mathrm{nM}$ están relacionadas con esta acción indirecta de la ET-1 $(1,25,36)$. Este fenómeno puede ser exagerado en condiciones patológicas como en los pacientes hipertensos, particularmente en presencia de polimorfismo del gen PreproET-1 (39). También se ha visto que ET-1 puede incrementar los niveles plasmáticos de aldosterona, interviniendo en su biosíntesis a nivel de la zona glomerulosa, la finalidad es incrementar el tono vascular (29). En la tabla 4 se expresa la función que ejerce la endotelina-1 sobre cada receptor, teniendo en cuenta el órgano implicado y el tipo celular, donde se indica que las células del músculo liso vascular estimuladas a través de los receptores ETA ejercen el mayor efecto constrictor y la célula endotelial activada por medio del receptor ETB ejerce el mayor efecto que otras células con la que se han comparado en este caso generando vasodilatación. 


\section{Comportamiento de ET-1 en células del músculo liso vascular humano}

La administración de ET-1 en infusión en seres humanos produce incremento de la presión arterial, dosis dependiente acompañada de una retención de sodio. La presión arterial media se incrementa en aproximadamente $10 \mathrm{mmHg}$. La ET-1, produce un efecto inótropo negativo, compromete el llenado diastólico de ambos ventrículos, disminuye el gasto cardíaco y reduce la frecuencia cardíaca. La circulación renal humana es extremadamente sensible al efecto vasoconstrictor de ET-1, la administración de $\mathrm{pmol} / \mathrm{Kg} /$ min produce un decremento de $25 \%$ del flujo plasmático renal y un incremento en $45 \%$ de la resistencia vascular renal estos efectos duran aproximadamente 3 horas (7).

Figura 5. Interacción entre ET-1 y receptor de tipo A. Esta interacción se produce en las células de músculo liso vascular, se generan los siguientes hechos claramente identificados: uno de ellos es la activación de una proteína $G \square$ sensible, este evento producirá la activación de la fosfolipasa C (PLC) haciendo que se produzca 1,3,5 inositol- tri- fosfato (IP3) y diacilglicerol (DAG), la acción posterior del IP3 es interactuar con sus receptores localizados en el retículo sarcoplásmico, haciendo que se produzca la liberación de Ca+2 al medio citoplasmático, ésta sería una vía para generar vasoconstricción. Adicionalmente, se producirá la activación de la fosfolipasa A (PLA2), por esta vía se libera tromboxano A2 que también colaborará con la producción de vasoconstricción. Además es posible que en forma tardía directamente se produzca la activación de canales dependientes de voltaje a través de la despolarización de la membrana plasmática de esta forma se permite ingresar calcio del medio extracelular al citoplasma, este mecanismo también va a colaborar con la vasoconstricción. Modificado de Reid J. J.Clinical and Experimental Pharmacology and Physiology (15).

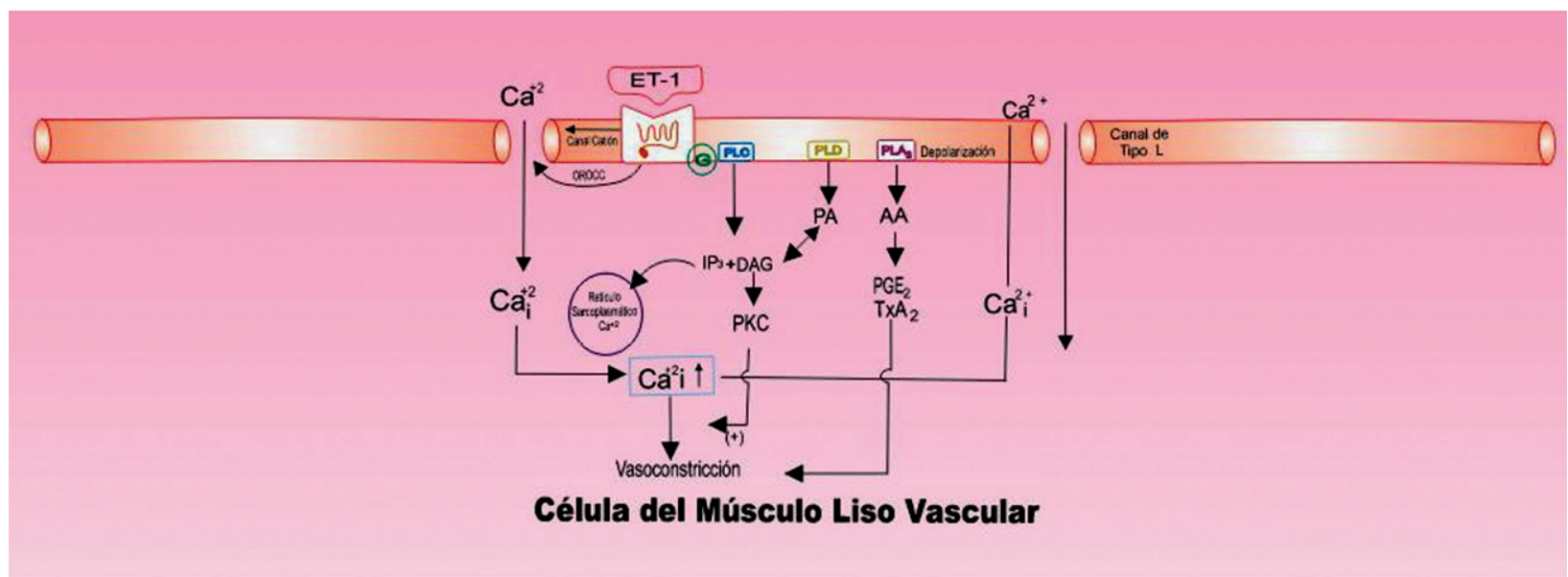

Se puede concluir que la vasoconstricción producida por la ET-1 se debe a:

a. La vasoconstricción inducida inicialmente por ET-1 puede ser inducida por la liberación de calcio del retículo sarcoplásmico mediado por la activación de la fosfolipasa $\mathrm{C}$.

b. El ingreso de calcio extracelular es necesario para el mantenimiento de la contracción, este hecho es mediado por la apertura de los canales calcio de tipo L, así como de otros canales como los canales catiónicos no selectivos para el calcio y canales operados por almacenamiento de calcio (35).

En la figura 5 se expone la liberación de ET-1 y su interacción con el receptor específico ETA y su accionar a través de segundos mensajeros. En la figura 6 se expone un resumen de todos los receptores que favorecen la vasoconstricción dependiente del endotelio vascular, se resalta la importancia del calcio como segundo mensajero que ejecuta la función sobre el músculo liso vascular. 
Figura 6. Los diferentes mediadores (agonistas) que actuando sobre su receptor van a lograr incrementar el calcio intracitoplasmático (Ca+2i) a expensas de la liberación de calcio del retículo sarcoplásmico y el ingreso del medio extracelular, este trae como consecuencia activar la maquinaria quinasa de cadena leve de miosina, actuando sobre la actina miosina y produciendo la vasoconstricción. Adaptado de Heriques T. et al. Faculda de Medicina da Universidade do Porto. Regulacao do tono vascular (40).

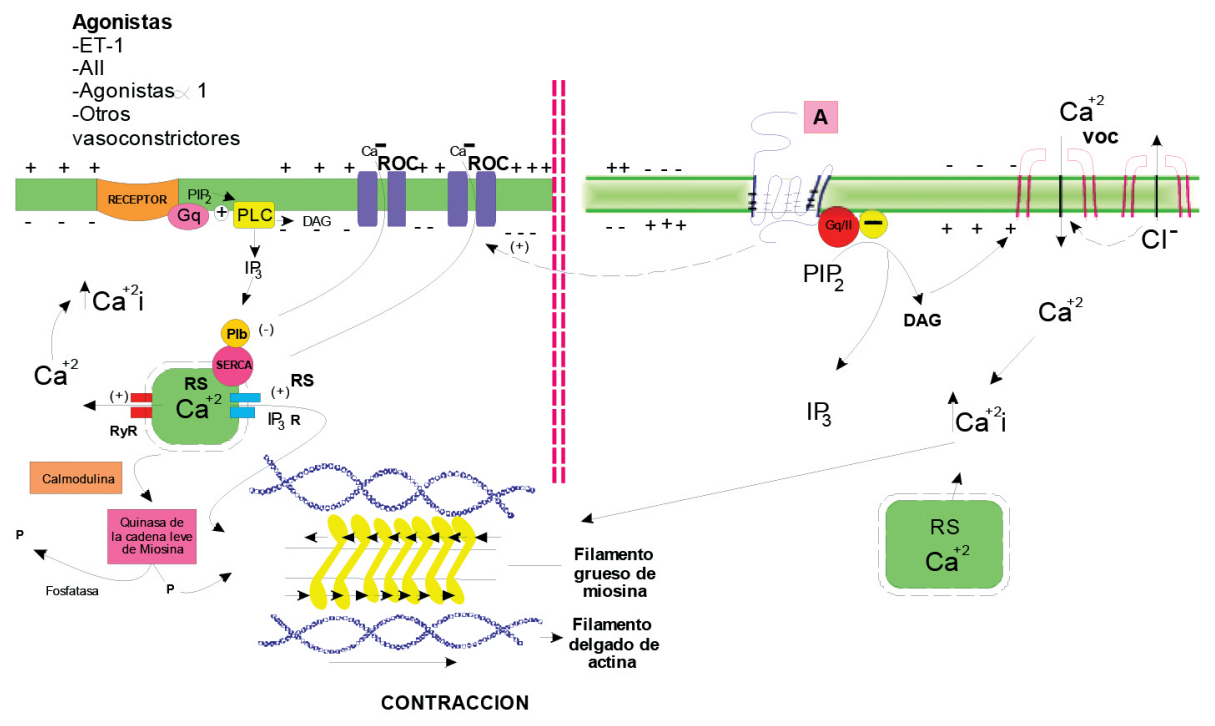

Diversos mecanismos de la vasoconstricción dependiente del endotelio

Tabla 4. Expresión y función de receptores de ET-1 en condicionesfisiológicas

\begin{tabular}{|c|c|c|c|c|}
\hline Órgano y tipo celular & Función & ETA & ETB & Referencias \\
\hline $\begin{array}{l}\text { Célula endotelial } \\
\text { Músculo liso vascular } \\
\text { Corazón } \\
\text { Vasculatura coronaria } \\
\text { Cardiomiocito } \\
\text { Pulmón } \\
\text { Arteria pulmonar } \\
\text { Riñón } \\
\text { Arteria renal } \\
\text { Arteriola aferente } \\
\text { Arteriola eferente } \\
\text { Vasculatura cortical } \\
\text { Vasculatura medular } \\
\text { Célula mesangial } \\
\text { Cerebro } \\
\text { Vasculatura cerebral } \\
\text { Hepatocitos } \\
\text { Neuronas } \\
\text { Osteoblastos } \\
\text { Queratinocitos } \\
\text { Adipositos } \\
\text { Fibroblastos } \\
\text { Astrocito } \\
\text { Otros órganos } \\
\text { Glándula adrenal } \\
\text { Ojo }\end{array}$ & $\begin{array}{l}\text { Vasodilatación } \\
\text { Vasoconstricción } \\
\text { Vasoconstricción } \\
\text { Vasodilatación } \\
\text { Inotrópico } \\
\text { Vasoconstricción } \\
\text { Vasodilatación } \\
\text { ET-1 eliminación } \\
\text { Vasoconstricción } \\
\text { Vasodilatación } \\
\text { Vasoconstricción } \\
\text { Vasoconstricción } \\
\text { Vasodilatación } \\
\text { Vasoconstricción } \\
\text { Vasodilatación } \\
\text { Contracción } \\
\text { Vasoconstricción } \\
\text { Vasodilatación }\end{array}$ & $\begin{array}{c}(+)(*) \\
(+) \\
(+) \\
\\
(+) \\
\\
\\
\\
+ \\
\\
+ \\
+ \\
+ \\
+ \\
+ \\
? \\
+ \\
? \\
+ \\
+ \\
+ \\
+ \\
+ \\
+ \\
+ \\
? \\
? \\
? \\
? \\
?\end{array}$ & $\begin{array}{c}+ \\
+ \\
\text { más } \\
+ \\
(+) \\
\\
+ \\
+ \\
+ \\
\\
+ \\
+ \\
+ \\
\\
+ \\
\\
+ \\
? \\
? \\
? \\
+ \\
+ \\
+ \\
+ \\
+ \\
? \\
+ \\
? \\
? \\
?\end{array}$ & $\begin{array}{l}(4,11,13,27) \\
(14,15,25,26) \\
(17,30,32) \\
(5,41)\end{array}$ \\
\hline
\end{tabular}




\section{Aplicaciones clínicas de endotelina 1}

La acción de ET-1 se describe en múltiples órganos y sistemas con funciones especificas. En la tabla 5 se describen las acciones biológicas que cumple ET-1 sobre los vasos sanguíneos, corazón, riñón, sistema neuroendocrino entre otros, cabe señalar que estos efectos son en condiciones fisiológicas.

Tabla 5. Acciones biológicas de las endotelinas.

\begin{tabular}{|c|c|}
\hline & Referencias \\
\hline $\begin{array}{l}\text { Efectos en los vasos sanguíneos y cardiovasculares } \\
\text { Contracción del músculo liso vascular. } \\
\text { Vasoconstricción coronaria, proliferación celular. } \\
\text { Efecto inotrópico y cronotrópico positivo bajo condiciones fisiológicas. } \\
\text { Disminución del gasto cardíaco. } \\
\text { Efecto depresor seguido de sostenido efecto vasopresor. } \\
\text { Remodelamiento en insuficiencia cardíaca, arritmogénesis. } \\
\text { Estimulación de la producción de óxido nítrico y prostaciclina vía receptores ETB } \\
\text { Las venas son más sensibles que las arterias } \\
\text { Efectos Renales } \\
\text { Vasoconstricción renal (arteriola eferente y aferente) por acción sobre receptor } \\
\text { tipo A. } \\
\text { Reducción de la tasa de filtración glomerular. } \\
\text { Flujo plasmático renal y reabsorción de sodio (por acción sobre receptor tipo B). } \\
\text { ET-1 disminuye el flujo del cloro en la rama ascendente delgada de Asa de Henle, } \\
\text { así contribuye con el efecto natriurético (vía ETB) } \\
\text { Efectos sobre el músculo liso } \\
\text { Contracción de músculo liso no vascular. } \\
\text { Vía aérea, intestino y útero. } \\
\text { Efectos neuroendocrinos } \\
\text { Incrementa los niveles del péptido natriurético auricular ( ANP), renina, } \\
\text { aldosterona y catecolaminas. } \\
\text { Modula de la sinapsis neuronal. } \\
\text { Otros efectos } \\
\text { Mitogénesis } \\
\text { Activación de la expresión génica de proto-oncogenes. } \\
\text { Efectos pulmonares } \\
\text { ET-1 induce bronco-constricción, este efecto se produce por estimulación de } \\
\text { tromboxano. } \\
\text { Depuración de ET-1. }\end{array}$ & $\begin{array}{l}(10,42) \\
(29,43) \\
(23,30)\end{array}$ \\
\hline
\end{tabular}

\section{Endotelina -1 (ET-1) y enfermedad}

Se ha demostrado que en condiciones patológicas la concentración de endotelina-1 se incrementa y que la relación proporcional en la expresión del número de receptores varía, haciendo más acentuada la presencia de los isotipos ETB. Estos hechos tendrían implicancias en la presencia y perpetuación de los estados mórbidos. En la tabla 6 se enumeran las principales patológicas donde se ha demostrado que ET-1 está en mayor concentración. 
Tabla 6. Concentración incrementada de ET - 1 y condiciones clínicas

\begin{tabular}{|l|l|}
\hline \multicolumn{1}{|c|}{ Condición Clínica } & \multicolumn{1}{|c|}{ Referencias } \\
\hline Shock cardiogénico & $(29,35,41,42,44)$ \\
Infarto de miocardio & $(39,45)$ \\
Hipertensión arterial & \\
Hipertensión asociada a embarazo & \\
Retardo del crecimiento intrauterino & \\
Arterioesclerosis & \\
Enfermedad de Raynaud & \\
Lupus eritematoso sistémico & \\
Uremia & \\
Sepsis & \\
Cirugía & \\
Trauma & \\
Enfermedad de Graves & \\
Cáncer & \\
Diabetes/resistencia a insulina & \\
Hipertensión pulmonar & \\
Arterioesclerosis & \\
Insuficiencia cardíaca & \\
Insuficiencia renal: nefrotoxicidad por ciclosporina o sustancia de contraste & \\
Esclerodermia & \\
\hline
\end{tabular}

\section{PUNTOS CLAVE PARA RECORDAR}

\section{Endotelina-1: vasoconstrictor intrínseco del endotelio vascular}

- La endotelina-1 (ET-1) es el vasoconstrictor más potente hasta ahora conocido por el hombre, incluso es 10 veces más potente que la angiotensina II. Existen 2 tipos de endotelina-1, siendo la endotelina de 21 aminoácidos la que tiene mayor actividad y potencia biológica sobre la de 31 aminoácidos. Existen otras 02 isoformas de endotelina denominadas ET-2 y ET-3.

- Los lugares de producción de endotelinas son diversos en la especie humana, sin embargo, podemos señalar como centros de mayor producción para ET-1 a las células endoteliales, para ET-2 se ha señalado a las células epiteliales renales y las células del estroma. Para ET-3 se ha identificado como las células de mayor producción a las neuronas glía e intestino.

- Los factores que estimulan la síntesis de ET-1 son múltiples, pero la hipoxia, isquemia son los más importantes. Siendo los inhibidores más importantes de su liberación el óxido nítrico, prostaglandinas E2, I2, y el péptido natriurético auricular y cerebral.
- Se han identificado dos tipos específicos de receptores de endotelinas denominados receptores de tipo A y B. Las células del endotelio expresan en mayor cantidad receptores de tipo $\mathrm{B}$, siendo su mayor acción sobre esta célula la vasodilatación. La célula del músculo liso vascular expresa mayor cantidad de receptores de tipo A, logrando en estas células vasoconstricción.

- La potencia de ET-1 es mayor sobre los receptores de tipo A que la ET-2 y ET-3. La potencia de ET-1 sobre receptores de tipo B es igual a ET-2 y ET-3.

- La ET-1 en condiciones patológicas se incrementa su producción, tanto es así que se ha demostrado su elevación en enfermedades agudas como crónicas, podemos señalar como es el caso de la hipertensión pulmonar, infarto agudo de miocardio, arterioesclerosis, lupus, sepsis, cirugías, cáncer, diabetes mellitus, insuficiencia cardíaca entre otras.

- La FDA ha aprobado el uso de Bosetan, un antagonista no selectivo de los receptores de endotelina de administración oral, para el tratamiento de hipertensión pulmonar primaria. 


\section{Referencias}

1. Ohlstein E, Douglas SA. Endothelin-1 modulates vascular smooth muscle structure and vasomotion: implications in cardiovascular pathology. Drug Develop Res. 1993; 29: 108-128.

2. Masaki T. Historical review: endothelin. Trends Pharmacol Sci.2004; 25(4): 219-224.

3. Shah R. Endothelins in health and disease. Eur J of Intern Med. 2007; 17: 272-282.

4. Estrada V. Endotelina, un nuevo peptido regulador cardiovascular. [Tesis]. Universidad Complutense de Madrid; 1993.

5. Trow TK, Taichman DB. Endothelin receptor blockade in the management of pulmonary arterial hypertension: selective and dual antagonism. Resp Med. 2009; 103: 951-962.

6. Moncada S, Higgs A. The vascular endothelium I. Springer -Verlag Berlin Heidelberg. 2006.

7. Vallance P. Vascular endothelium in human physiology and pathophysiology. Amsterdam: Taylor \& Francis e library; 2004.

8. Hynynen M, Khalil R. The vascular endothelin system in hypertension - recent patents and discoveries. Recent pat cardiovasc drug discov. 2006; 1(1): 95-108.

9. Alonso D, Radomski. The nitric oxide - endothelin -1 connection. Heart Fail Rev. 2003; 8: 107-115.

10. Baltazares M, Crespo H, Ortega J, Sotres-Vega A, Baltazares ME. Sistema endotelina. Rev. Inst. Nal. Enf. Resp. Mex . 2005; 18(4): 308-320.

11. Kedzierski RM, Yanagisawa M. Endothelin system: The double-edged sword in health and disease. Annu Rev Pharmacol. 2001; 41: 851-876.

12. Jugdutt B.J. The role of nitric oxide in heart failure. Norwell, MA: Kluwer Academic Publishers; 2004.

13. Marasciulo FL, Montagnami M, Potenza MA. Endothelin -1: The yin and yang on vascular function. Curr Med Chem. 2006; 13: 1655-1665.

14. Prasad VS, Palaniswamy C, Frishman W. Endothelin as a clinical target in the treatment of systemic hypertension. Cardiol Rev. 2009; 17: 181-191.

15. La M, Reid JJ. Endothelin -1 and the regulation of vascular tone. Clin Exp Pharmacol P. 1995; 22: 315-323.

16. Rossi GP, Seccia TM, Albertin G, Pessina AC.. Measurement of endothelin: Clinical and research use. Ann Clin Biochem. 2000; 37: 608-626.

17. Melgarejo E. El endotelio 25 años después. Revista Med. 2005; 13(1): 45-61.

18. Toste R, Muscará M. Endothelin receptor antagonists: Another potential alternative for cardiovascular disease. Curr Drug Targets- Cardiovasc Haematol Disord. 2005; 5: 287-301.

19. Masaki T, Kimura S, Goto K. Molecular and vellular mechanism of endothelin regulation. Implications for vascular function. Circulation. 1991; 84: 1457-1468.

20. Masaki T, Yanagisawa M. Cardiovascular effects of the endothelins. Cardiovasc Drug Rev. 1990; 8(4): 373-385.

21. Benigni A, Remuzzi G. Endothelin antagonists. Lancet. 1999; 353: 133-38.

22. Comellas AP, Briva A. Role of endothelin-1 in Acute Lung Injury. Transl Res. 2009; 153: 263-27.

23. Balakrishnan S, Pandhi P. Endothelins: a brief review. Indian $\mathrm{J}$ Pharmacol. 1997; 29: 281-288.

24. Scheider MP, Boesen E. I and Pollock DM. Contrasting actions of endothelin eta and etb receptor in cardiovascular disease. Annu. Rev. Pharmacol. Toxicol. 2007; 47: 731-759.
25. Kurtel H, Ghandour S. Endothelins and inflammation: the gastrointestinal system. Pathophysiology. 1999; 6: 77-89.

26. Motte S, McEntee, Naeije R. Endothelin receptor antagonists. Pharmacol Ther. 2006; 110: 386-414.

27. Bohm F, Pernow J. The importance of endothelin-1 for vascular dysfunction in cardiovascular disease. Cardiovasc Res. 2007; 76: 8-18.

28. Galié N, Manes A, Brazi A. The endothelin system in pulmonary arterial hypertension. Cardiovasc Res. 2004; 61: 227-237.

29. Leppaluoto J, Ruskoaho H. Endothelin eptides: Biological activies, celular signaling and clinical significance. Ann Med. 1992; 24: 153-161.

30. Agapitov AV, Hayes WG. Role of endothelium in cardiovascular disease. J Renin Angiotensin Aldosterone Syst. 2002; 3: 1-15.

31. D'Orleans-Juste PD, Houde M, Rae GA. Bkaily G, Carrier E, Simard E. Endothelin-1(1-31): From 1. chymasa-dependet syntesis to cardiovascular pathologies. Vascul Pharmacol. 2008; 49: 51-62.

32. Kirkby NS, Hadoke PW, Bagnall AJ. Webb DJ. The endothelin sytem as a therapeutic target in cardiovascular disease.: great expectations or bleak house? Br J Pharmacol. 2008 ; 153:11051119.

33. Davenport AP. International union of pharmacology. XXIX. Update on endothelin receptor nomenclature. Pharmacol Rev. 2002; 54: 219-226.

34. Neil F. Fisiología de la tonicidad del endotelio vascular y disfunción del endotelio-parte1. Et vita. 2007; 2(2):18-26.

35. Neil F. Medicina vascular: Implicancias del endotelio en la regulación del tono vascular. Lima: Fondo Editorial UPT-PERU; 2010.

36. Ohlstein EH, Elliot JD, Feuerstein GZ, Ruffolo R. Endothelin receptors: receptor classification, novel receptor antagonists, and potential therapeutic targets. Med ResRev. 1996;16(4): 365-390.

37. Duru F, Barton M, luscher T. F. et al. Endothelin and cardiac arrthythmias: do endothelin antagonists heve a therapeutic potential as antiarrhythmic drugs? Cardiovasc Res. 2001; 49: 272-280.

38. Kim N, Rubin LJ. Endothelin in health and disease: endothelin receptor antagonists in the management of pulmonary artery hypertension. J Cardiovasc Pharmacol Ther. 2002; 7(1): 9-19.

39. Savioa C, Schiffrin EL. Significance of recently identified peptides in hypertension: Endothelin, natriuretic pepetides, adrenomedullin, leptin. Med Clin N Am. 2004; 88: 39-62.

40. Heriques T, Olivera S, Leite A. Regulación del tono vascular. Facultad de Medicina de la Universidad de Porto 2002/03.

41. Aliaga R. Reactividad de las arterias coronarias frente a factores vasoactivos derivados del endotelio. Valencia: Universitat de Valencia. Servie de publicacions ; 2005.

42. Barton M, Yanagisawa M. Endothelin: 20 years from discovery to therapy. Can J. Physiol. Pharmacol. 2008; 86: 485-498.

43. Schorlemmer A, Matter ML, Shohet RV. Cardioprotective signaling by endothelin. Trends Cardiovasc Med. 2008; 18: 233-239.

44. Gray GA, Battistini B, Webb DJ. Endothelins are potent vasoconstrictor, and much more besides. Trend Pharmacol Sci. 2000; 21: 38-40.

45. Clozel M, Flores S. Endothelin receptor as drug targets in chronic cardiovascular disease: the rationale for dual antagonism. Drug Develop Res. 2006; 67: 825-834. 